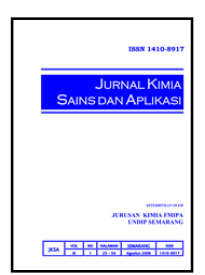

\title{
Sintesis Amil Sinamat dari Sinamaldehid dan Uji Aktivitas sebagai Bahan Aktif Tabir Surya
}

\author{
Adityo Anggadita ${ }^{a}$, Ngadiwiyana $^{\mathrm{a}^{*}}$, Ismiyarto $^{\mathrm{a}}$ \\ a Organic Chemistry Laboratory, Chemistry Department, Faculty of Sciences and Mathematics, Diponegoro University, Jalan Prof. \\ Soedarto, Tembalang, Semarang \\ * Corresponding author: ngadiwiyana@live.undip.ac.id
}

\begin{tabular}{|c|c|}
\hline Article Info & Abstract \\
\hline $\begin{array}{l}\text { Keywords: } \\
\text { synthesis; } \\
\text { oxidation; } \\
\text { estherification; } \\
\text { cinnamaldehyde; } \\
\text { sunscreen }\end{array}$ & $\begin{array}{l}\text { Adverse effects caused by sunlight can cause skin to be scaly black, hyperpigmentation } \\
\text { and skin cancer. The sunscreen preparation is one way that can be used to prevent this } \\
\text { effect. One of the active compounds that can be used in sunscreen preparations is a } \\
\text { cinnamic derivative. In this research, synthesis of amyl cinnamic acid from } \\
\text { cinamaldehid using oxidation and esterification method was conducted. Determination } \\
\text { of amyl cinnamic activity was done by UV-Vis spectrophotometry method by } \\
\text { determining SPF (Sun Protection Factor) value. The resulting amyl cinnamate was } \\
\text { brownish liquid and can be used as a constituent of sunscreen which provides maximum } \\
\text { protection against UV-B rays at } 25 \mathrm{\mu g} / \mathrm{mL} \text { concentration with an SPF value of } 12.88 \text {. }\end{array}$ \\
\hline
\end{tabular}

\section{Abstrak}

Kata kunci:

Sintesis; oksidasi; esterifikasi; sinamaldehid; tabir surya

\begin{abstract}
Efek merugikan yang ditimbulkan oleh sinar matahari dapat menyebabkan kulit menjadi hitam bersisik, hiperpigmentasi dan kanker kulit. Sediaan tabir surya adalah salah satu cara yang bisa digunakan untuk mencegah efek ini. Salah satu senyawa aktif yang bisa digunakan dalam sediaan tabir surya adalah turunan sinamat. Dalam proses ini dilakukan sintesis amil sinamat dari sinamaldehid dengan menggunakan metode oksidasi dan esterifikasi. Penentuan aktivitas amil sinamat dilakukan dengan metode spektrofotometri UV- Vis dengan menentukan nilai SPF (Sun Protection Factor). Amil sinamat yang dihasilkan berupa cairan berwarna coklat dan dapat digunakan sebagai penyusun sediaan tabir surya yang memberikan proteksi maksimum terhadap sinar UVB pada konsentrasi $25 \mu \mathrm{g} / \mathrm{mL}$ dengan nilai SPF sebesar 12,88.
\end{abstract}

\section{Pendahuluan}

Sinar matahari dapat menyebabkan kulit menjadi hitam bersisik, hiperpigmentasi dan kanker kulit. Penyebab utamanya adalah sinar ultraviolet, terutama radiasi sinar ultraviolet A dan ultraviolet B. Sediaan tabir surya salah satu cara yang bisa digunakan untuk mencegah efek tersebut karena mengandung bahan aktif penangkal sinar ultraviolet yang mengganggu kesehatan kulit. Sediaan tabir surya merupakan sediaan kosmetika yang digunakan dengan maksud menyerap secara efektif cahaya matahari terutama pada daerah gelombang ultraviolet, sehingga dapat mencegah terjadinya gangguan kulit arena cahaya matahari [1]
Pengembangan tabir surya di negara-negara maju sebagian besar penelitiannya banyak dilakukan dalam mendesain dan menemukan produk atau bahan aktif tabir surya yang memiliki kemampuan melindungi dari paparan sinar ultraviolet yang lebih baik dengan efek samping yang seminimal mungkin terhadap penggunaannya [2]. Seiring bertambahnya waktu dan kebutuhan terhadap senyawa aktif tabir surya, perlu dipikirkan dan pemanfaatan bahan alam melimpah sebagai bahan aktif sediaan tabir surya. Indonesia adalah penghasil minyak atsiri di dunia namun diekspor dalam bentuk mentahnya yang harganya relatif murah dan kurang memberikan tambahan pemasukan negara. Berdasarkan hal inilah, perlu adanya peningkatan mutu 
minyak atsiri dengan mengisolasi komponenkomponen penyusunnya dan mengubah menjadi senyawa turunannya yang memiliki nilai jual yang lebih tinggi.

Turunan sinamat merupakan salah satu golongan zat aktif tabir surya. Senyawa ini memiliki gugus kromofor yang dapat menyerap radiasi pada daerah ultraviolet. Komponen utama dari minyak kayu manis adalah sinamaldehid [3]. Salah satu golongan zat aktif tabir surya adalah senyawa turunan sinamat yaitu ester sinamat [4]. Senyawa tabir surya melindungi kulit dengan menyerap atau memantulkan radiasi UV [5]. Sinamaldehid adalah senyawa turunan sinamat yang dapat disintesis dari sinamaldehid.

Sintesis amil sinamat melalui 4 tahapan. Tahap pertama adalah isolasi sinamaldehid dari minyak kayu manis dengan distilasi fraksinasi pengurangan tekanan. Tahap kedua adalah oksidasi sinamaldehid menjadi asam sinamat menggunakan asam kromat $\left(\mathrm{H}_{2} \mathrm{CrO}_{4}\right)$. Dengan menggunakan oksidator kuat ini diharapkan dapat dihasilkan asam sinamat dari sinamaldehid. Tahap ketiga adalah esterifikasi asam sinamat menggunakan amil alkohol sehingga didapatkan amil sinamat. Tahap terakhir pengukuran efektifitasnya dengan menggunakan spektrofotometri UV-VIS untuk mengukur nilai SPF (sun protection factor) dan menentukan jenis perlindungan dari senyawa hasil sintesis.

\section{Metodologi}

\subsection{Isolasi Sinamaldehid dari Minyak Kayu Manis}

Sebanyak $40 \mathrm{~mL}$ minyak kayu manis. Kemudian dimasukkan kedalam labu leher dua dilakukan isolasi dengan cara distilasi fraksinasi pengurangan tekanan. Hasil yang didapatkan yaitu senyawa sinamaldehid. Hasil distilasi dilakukan pengujian dengan GC-MS dan FTIR.

\subsection{Oksidasi Sinamaldehid menjadi Asam Sinamat}

Dalam labu leher tiga $250 \mathrm{~mL}$ dimasukkan $4 \mathrm{~mL}$ sinamaldehid dilarutkan dalam $100 \mathrm{~mL}$ dietil eter. Sambil diaduk ditambahkan 7,9 g yang telah dilarutkan dalam $100 \mathrm{~mL}$ aquadest sedikit demi sedikit. Kemudian penambahan 4 tetes KTF dan 2 tetes $\mathrm{H}_{2} \mathrm{SO}_{4}$. Setelah itu, campuran diaduk selama 6 jam lalu didinginkan dan dibiarkan mencapai suhu kamar. Selanjutnya campuran disaring untuk memisahkan endapan $\mathrm{CrO}_{2}$ yang terbentuk. Kemudian campuran diektraksi dengan dietil eter untuk memisahkan antara fasa air dan fasa organik, dimana pada fasa organik terdapat asam sinamat. Filtrat yang dihasilkan dievaporasi menggunakan evaporator buchi untuk menguapkan pelarut sisa dan kemudian endapannya dikeringkan dalam desikator. Hasil yang diperoleh dianalisa dengan spektrofotometer FTIR.

\subsection{Esterifikasi Asam Sinamat dengan Amil alkohol}

Ke dalam labu alas bulat leher tiga kapasitas $250 \mathrm{~mL}$ yang dilengkapi dengan termometer, dimasukkan 2,5 g asam sinamat hasil sintesis, $40 \mathrm{~mL}$ amil alkohol, 2 tetes asam sulfat pekat dan pengaduk magnet kemudian campuran diaduk selama 6 jam. Hasil refluks didinginkan dan dimurnikan dengan distilasi fraksinasi pengurangan tekanan. Selanjutnya hasil yang diperoleh dianalisis dengan GC-MS.

\subsection{Pengukuran Aktivitas Amil Sinamat sebagai Bahan Aktif Tabir Surya dengan Spektrofotometri UV-Vis}

Penentuan aktivitas sebagai tabir surya dilakukan dengan menentukan nilai SPF secara in vitro dengan metode spektrofotometri. Senyawa amil sinamat dilarutkan dalam etanol dengan konsentrasi $5 \mathrm{\mu g} / \mathrm{ml}$ hingga $30 \mu \mathrm{g} / \mathrm{ml}$. Kemudian diukur serapannya pada panjang gelombang $200 \mathrm{~nm}$ sampai $400 \mathrm{~nm}$. Selanjutnya dihitung nilai log SPF yang merupakan nilai rata-rata dari serapan dan kemudian ditentukan nilai SPF serta jenis proteksi tabir surya dari amil sinamat.

\section{Hasil dan Pembahasan}

\subsection{Isolasi Sinamaldehid dari Minyak Kayu Manis}

Dalam penelitian ini menggunakan minyak kayu manis perdagangan sebanyak $50 \mathrm{~mL}$. Sinamaldehid dapat diisolasi dari minyak kayu manis dengan metode distilasi fraksinasi pengurangan tekanan. Metode ini digunakan karena minyak kayu manis mengandung campuran senyawa-senyawa yang memeiliki titik didih tinggi, maka perlu adanya pengurangan tekanan agar senyawa yang ingin dipisahkan dapat menguap pada titik didih yang lebih rendah. Data hasil isolasi sinamaldehid menggunakan distilasi fraksinasi penurunan tekanan ditampilkan pada tabel 1 sebagai berikut:

Tabel 1. Hasil Isolasi Sinamaldehid

\begin{tabular}{cccc}
\hline Fraksi & $\begin{array}{c}\text { Suhu } \\
\text { terkondensasi } \\
\left({ }^{\circ} \mathrm{C}\right)\end{array}$ & $\begin{array}{c}\text { Tekanan } \\
\text { sistem } \\
(\mathrm{mmHg})\end{array}$ & $\begin{array}{c}\text { Volume } \\
\text { distilat } \\
(\mathrm{mL})\end{array}$ \\
\hline I & 55 & $85 \mathrm{mmHg}$ & 1,5 \\
II & 64 & $85 \mathrm{mmHg}$ & 35,5 \\
III & 80 & $85 \mathrm{mmHg}$ & 3,0 \\
\hline
\end{tabular}

Hasil distilasi fraksinasi pengurangan tekanan pada fraksi II dianalisis dengan Gas Chromatoghapy-Mass Spectrometry (GC-MS)

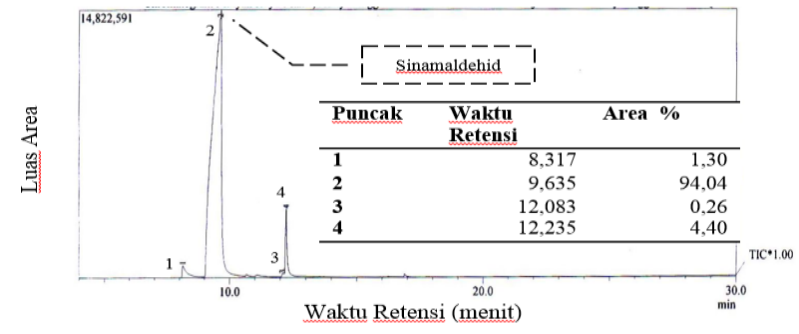

Gambar 1. Gambar Kromatografi Gas fraksi II Sinamaldehid

Berdasarkan analisis GC-MS pada gambar 1, diketahui bahwa sinamaldehid muncul pada puncak kedua dengan waktu retensi 9,635 menit dan 
kelimpahan 94,04\%. Sedangkan pada gambar 2 menunjukkan spektrum massa sinamaldehid dengan $\mathrm{M}^{+}$: 132 sesuai berat molekul sinamaldehid.

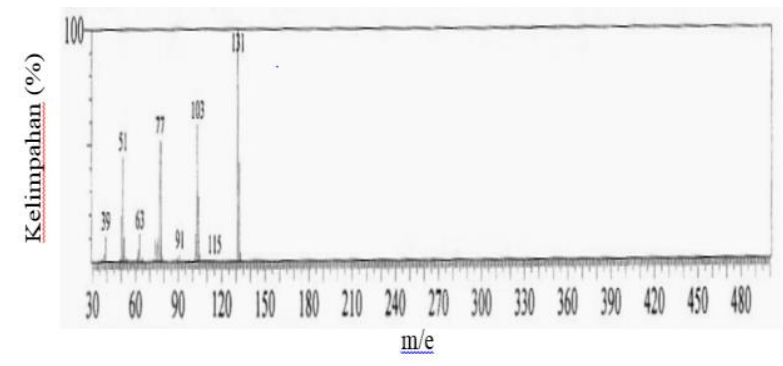

Gambar 2 Spektrogram Sinamaldehid

Hasil analisis fraksi II menggunakan spektrofotometer FTIR menghasilkan spektrum seperti yang tercantum pada gambar 3 di bawah ini:

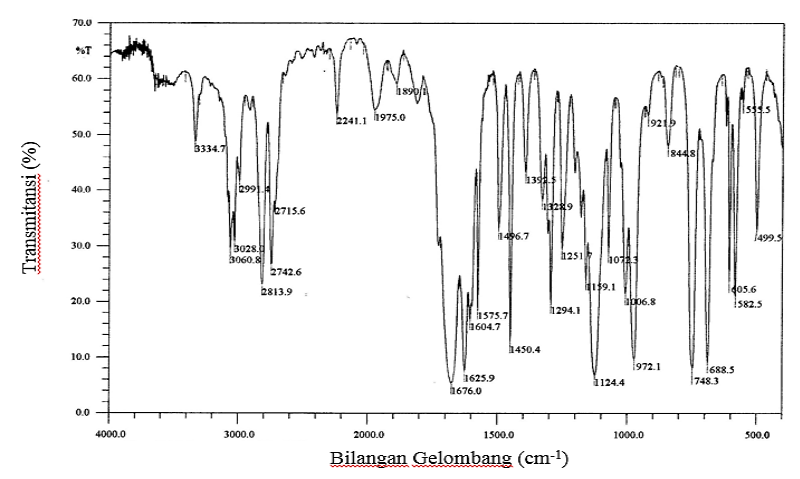

Gambar 3 Spektrum Infra Merah Sinamaldehid

Tabel 2 Serapan Gugus Fungsi Asam Sinamat

\begin{tabular}{cc}
\hline Bilangan Gelombang $\left(\mathrm{cm}^{-1}\right)$ & Gugus Fungsi \\
\hline 1676,00 & $\mathrm{C}=\mathrm{O}$ (karbonil) \\
2813,9 dan 2742,6 & $-\mathrm{CHO}$ (aldehid) \\
1604,77 & $\mathrm{C}=\mathrm{C}$ (alkena) \\
3060,88 & $\mathrm{C}-\mathrm{H} \mathrm{sp}{ }^{2}$ \\
\hline
\end{tabular}

\subsection{Oksidasi Sinamaldehid menjadi Asam Sinamat}

Oksidasi sinamaldehid dilakukan dengan oksidator asam kromat menghasilkan asam sinamat dengan rendemen $41,99 \%$ dan titik lelehnya $119-125^{\circ} \mathrm{C}$. Tahap awal oksidasi adalah melarutkan $\mathrm{CrO}_{3}$ dalam air dan melarutkan sinamaldehid dalam dietil eter. Sinamaldehid dioksidasi melalui proses refluks pada suhu kamar selama 6 jam menggunakan pelarut dietil eter yang ditambahkan sedikit demi sedikit ke dalam larutan asam kromat dengan bantuan katalis transfer fasa (KTF). Tujuan penggunaan katalis transfer fasa adalah untuk meningkatkan hasil reaksi, karena reaktan terdapat dalam sistem dua fasa, yaitu fasa air dan fasa organik. Fasa organik merupakan sinamaldehid yang dilarutkan dalam dietil eter sedangkan fasa air merupakan oksidator $\left(\mathrm{CrO}_{3}\right)$ yang larut dalam air. Ke dua fasa tersebut tidak saling bercampur sehingga reaksi hanya terjadi pada antar permukaan kedua lapisan. Adanya penambahan katalis transfer fasa, maka dapat membantu perpindahan asam kromat yang larut dalam air melintasi antar muka kedua pelarut menuju sinamaldehid sehingga reaksi homogen dapat terjadi dan laju reaksi meningkat. Katalis yang digunakan adalah polyoxyethylene (20) sorbitan monolaurat atau polysorbate-20 yang relatif stabil dan tidak toksik. Gugus hidrofil dari senyawa ini adalah polieter atau disebut juga polyoxyethylene dan gugus hidrofobnya adalah asam laurat. Mekanisme reaksi oksidasi senyawa sinamaldehid menggunakan oksidator asam kromat disajikan pada gambar 4 sebagai berikut:

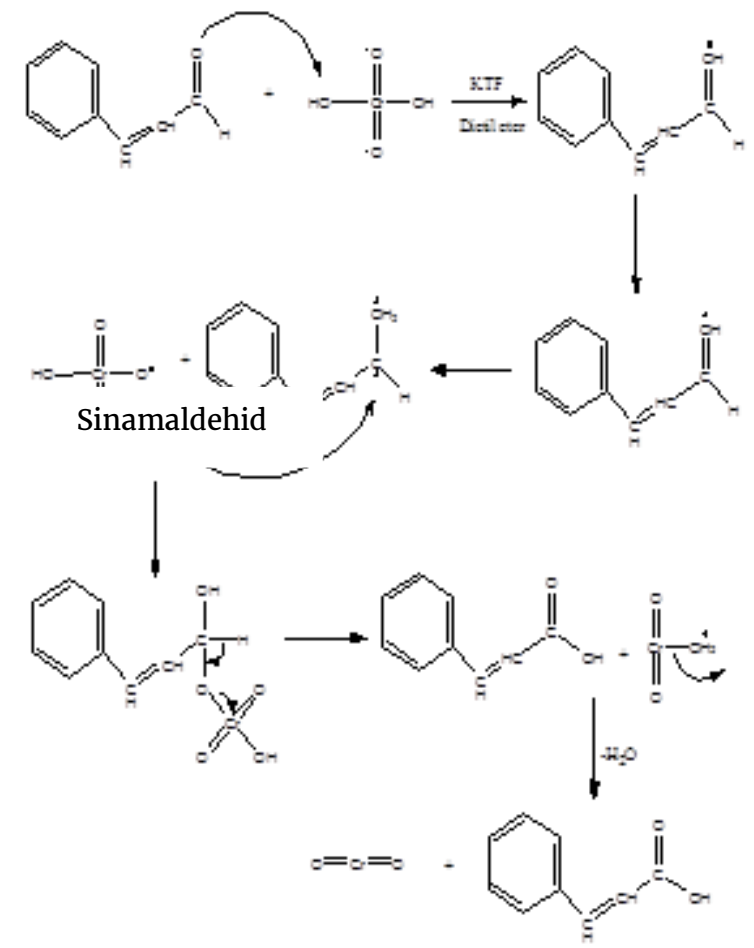

Gambar 4 Reaksi Oksidasi Sinamaldehid dengan Asam Kromat

Analisis asam sinamat ditentukan dengan analisis spektofotometer FTIR ditunjukkan pada gambar 5 sebagai berikut:

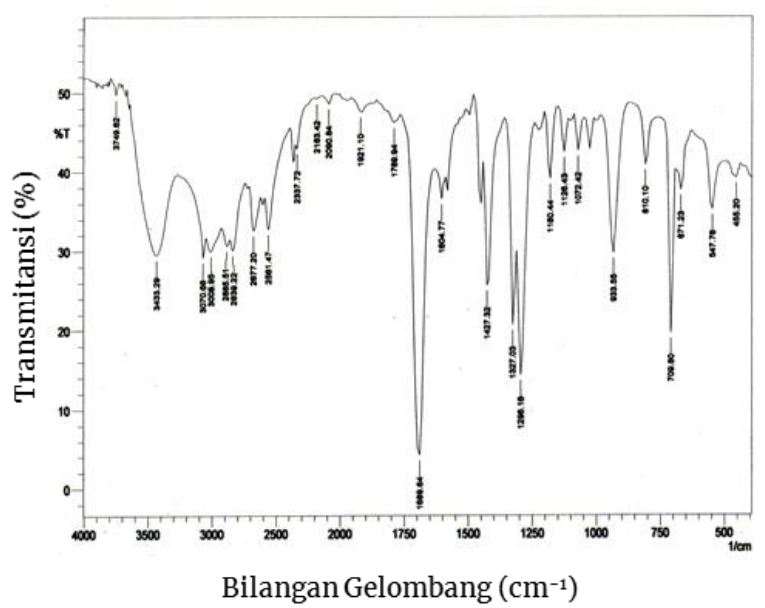

Gambar 5 Spektrum Infra Merah Asam Sinamat 
Tabel 3 Serapan Gugus Fungsi Asam Sinamat

\begin{tabular}{cc}
\hline $\begin{array}{c}\text { Bilangan Gelombang } \\
\left(\mathrm{cm}^{-1}\right)\end{array}$ & Gugus Fungsi \\
\hline 1689,64 & $\mathrm{C}=\mathrm{O}$ (karbonil) \\
1180,44 & $\mathrm{C}-\mathrm{O}$ (karboksilat) \\
3433,29 & $\mathrm{OH}$ \\
1604,77 & $\mathrm{C}=\mathrm{C}$ (alkena) \\
3070,68 & $\mathrm{C}-\mathrm{H} \mathrm{sp}^{2}$ \\
\hline
\end{tabular}

\subsection{Esterifikasi Asam Sinamat dengan Amil Alkohol}

Amil sinamat didapatkan dari hasil sintesis asam sinamat yang diesterkan dengan amil alkohol menggunakan katalis asam sulfat $\left(\mathrm{H}_{2} \mathrm{SO}_{4}\right)$ pekat. Selain sebagai pereaksi, amil alkohol juga berfungsi sebagai pelarut. Mekanisme reaksi esterifikasi amil sinamat disajikan pada gambar 6 sebagai berikut:

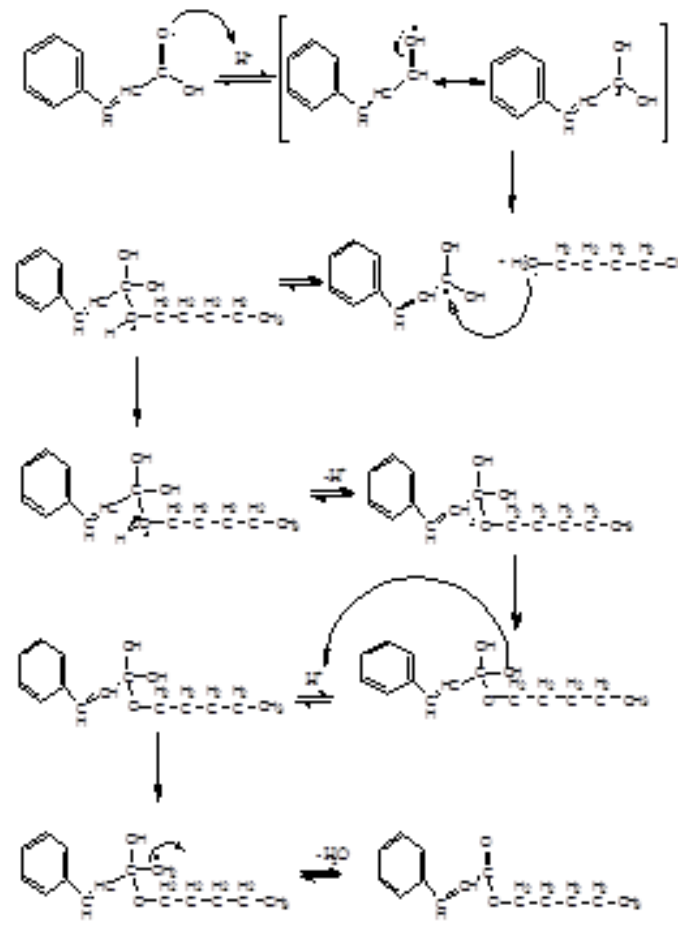

Gambar 6 Mekanisme Reaksi Esterifikasi Amil sinamat

Reaksi esterifikasi antara asam sinamat dengan amil alkohol diawali dengan protonasi asam sinamat dan selanjutnya terjadi reaksi substitusi nukleofilik oleh amil alkohol menghasilkan zat antara yang diikuti pelepasan molekul $\mathrm{H}_{2} \mathrm{O}$ sehingga menghasilkan senyawa amil sinamat. Kromatografi Gas dan spektogram amil sinamat disajikan pada gambar 7 dan III.8 di bawah. Diketahui bahwa senyawa amil sinamat terdapat pada puncak ketiga dengan waktu retensi 19,801 menit dan kelimpahan 58,69\% ditunjukkan pada gambar 7 sebagai berikut:

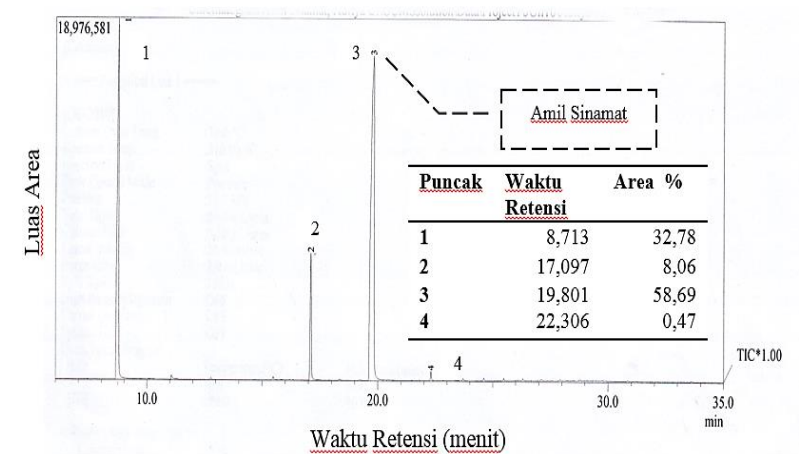

Gambar 7 Kromatografi Gas Hasil Esterifikasi Amil Sinamat

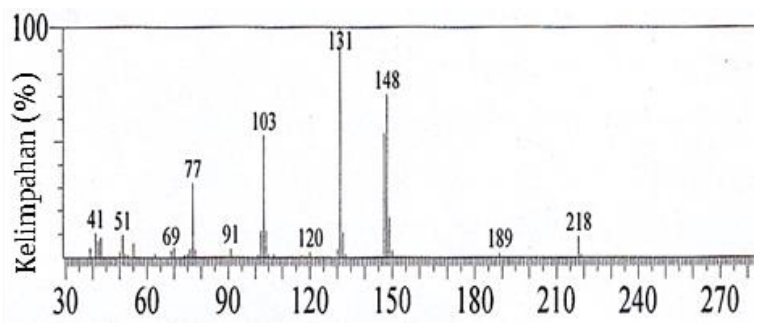

Gambar 8 Spektrogram Amil Sinamat

Spektogram pada gambar 8 menginformasikan nilai m/e 218 yang merupakan fragmen dari ion molekuler sesuai dengan berat molekul dari amil sinamat. Selanjutnya pola fragmentasi dari amil sinamat tercantum pada lampiran $\mathrm{H}$. Analisis produk dengan GC-MS menunjukkan bahwa terbentuk senyawa amil sinamat. Hasil esterifikasi didapatkan cairan coklat dan berbau harum dengan rendemen sebesar 80,73\%.

\subsection{Pengukuran Aktivitas Amil Sinamat sebagai Bahan Aktif Tabir Surya dengan Spektrofotometri UV-Vis}

Pengukuran aktivitas amil sinamat sebagai senyawa tabir surya dapat dilakukan dengan cara in vitro menggunakan spektrofotometri ultraviolet. Pengukuran dilakukan secara tidak langsung maksudnya adalah dengan cara mengukur nilai serapan cuplikan pada panjang gelombang ultra violet yaitu diantara $200 \mathrm{~nm}-$ $400 \mathrm{~nm}$ menggunakan spektrofotometri UV-Vis kemudian dihitung nilai SPF (Sun Protection Factor). Pengukuran absorbansi dilakukan dengan kisaran konsentrasi antara 5 - $30 \mu \mathrm{g} / \mathrm{mL}$ dengan menggunakan pelarut etanol yang diperkirakan memberikan proteksi minimum hingga proteksi ultra terhadap ultraviolet. Penggunaan pelarut etanol sebagai pelarut karena etanol pelarut yang tidak menganggu serapan senyawa terlarut amil sinamat. Berikut gambar 9 menampilkan kurva spektra UV-Vis amil sinamat.

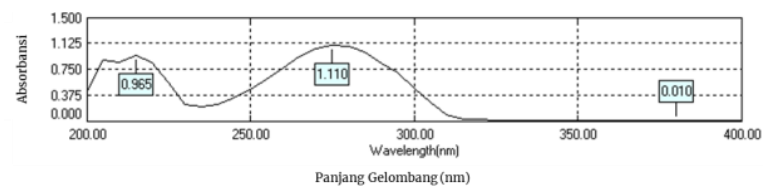

Gambar 9 Kurva Spektrofotometri UV-Vis Amil Sinamat 
Hasil analisis menggunakan spektrofotometri uvvis menunjukan adanya dua buah puncak. Puncak 275 nm merupakan puncak serapan maksimum gugus sinamoil dalam senyawa tersebut dan pada daerah panjang gelombang $215 \mathrm{~nm}$ yang menunjukkan adanya serapan sistem benzena.

Senyawa amil sinamat berdasarkan data spektrum UV-Vis menyatakan bahwa dapat menyerap pada panjang gelombang antara 240 - $315 \mathrm{~nm}$ yang merupakan daerah ultraviolet B. Persamaan SPF $=10^{\mathrm{A}}$ rerata digunakan untuk mencari besarnya nilai SPF masing-masing absorbansi amil sinamat. Kemudian penentuan jenis proteksinya untuk masing-masing konsentrasi. Senyawa tabir surya yang baik adalah senyawa tabir surya yang mampu memberikan perlindungan secara maksimum. Berikut ini nilai SPF amil sinamat disajikan pada tabel 2 sebagai berikut:

Tabel 2 Analisis Senyawa Amil Sinamat dengan UV-Vis

\begin{tabular}{ccc}
\hline Konsentrasi $\mu \mathrm{g} / \mathrm{mL}$ & Nilai SPF & Jenis Proteksi \\
\hline 7 & 2,1134 & Minimum \\
10 & 2,8973 & Minimum \\
15 & 4,7533 & Sedang \\
20 & 7,6032 & Ekstra \\
25 & 12,8824 & Maksimum \\
26 & 15,4881 & Ultra \\
\hline
\end{tabular}

Pada penelitian ini senyawa amil sinamat memberikan proteksi maksimum terhadap sinar UV-B pada konsentrasi $25 \mu \mathrm{g} / \mathrm{mL}$ dengan nilai SPF sebesar 12,8824, sedangkan proteksi minimum pada konsentrasi $7 \mu \mathrm{g} / \mathrm{mL}$. Senyawa dengan nilai SPF maksimum relatif lebih aman karena konsentrasi yang dibuat tidak terlalu besar sehingga mampu memmberikan proteksi terhadap kulit.

\section{Kesimpulan}

Sinamaldehid dapat diisolasi dari minyak kayu manis dengan cara distilasi fraksinasi pengurangan tekanan dengan kelimpahan sebesar 94,04\% dan rendemen sebesar 88,75\%. Asam sinamat dapat disintesis dari sinamaldehid melalui reaksi oksidasi dengan rendemen sebesar $41,99 \%$. Amil sinamat dapat disintesis melalui reaksi esterifikasi antara asam sinamat dengan amil alkohol. Hasil sintesis diperoleh berupa cairan coklat beraroma dengan rendemen $80,73 \%$ dan kemurnian 58,69\%. Amil sinamat memberikan proteksi maksimum terhadap sinar UV-B pada konsentrasi $25 \mu \mathrm{g} / \mathrm{mL}$ dengan nilai SPF sebesar 12,88 .

\section{Daftar Pustaka}

[1] A.C. Green, G.M. Williams, Point: sunscreen use is a safe and effective approach to skin cancer prevention, Cancer Epidemiology Biomarkers \& Prevention, 16 (2007) 1921-1922.

[2] C. Walters, A. Keeney, C.T. Wigal, C.R. Johnston, R.D. Cornelius, The spectrophotometric analysis and modeling of sunscreens, J. Chem. Educ, 74 (1997) 99.

[3] N.B. Adiwibawa, N. Ngadiwiyana, Identifikasi Senyawa Penyusun Minyak Kulit Batang Kayu Manis (Cinnamomum cassia) Menggunakan GCMS, Jurnal Kimia Sains dan Aplikasi 9(2006).

[4] L.F. do Nascimento, A.P. de Aguiar, E.P. dos Santos, Synthesis of new cinnamic derivatives as potential UV sunscreens.

[5] E.J. Collaris, J. Frank, Photoallergic contact dermatitis caused by ultraviolet filters in different sunscreens, International journal of dermatology, 47 (2008) 35-37. 